\title{
A FUNÇÃO PRAGMÁTICA DOS DIMINUTIVOS EM CORPORA ORAIS DAS VARIEDADES MADRILENA E CARIOCA $^{1}$
}

\section{PRAGMATIC FUNCTIONS OF DIMINUTIVES IN ORAL CORPORA OF MADRILENA AND CARIOCA VARIETIES}

\author{
Camilla Santero Pontes² \\ Universidade Federal da Bahia(UFBA)
}

Resumo: Este trabalho descritivo-comparativo tem por objetivo identificar quais são as funções morfopragmáticas dos diminutivos na atividade entrevista sociolinguística e observar se as formações diminutivas estão a serviço da construção de face do entrevistado para confrontar seus usos na variedade carioca do português e na variedade madrilena do espanhol. Para tanto foram analisadas doze entrevistas, sendo seis do projeto NURC-RJ e seis do projeto PRESEEA. Os dados analisados a partir da Morfopragmática (DRESSLER; MERLINI BARBARESI, 2020) e da Teoria de elaboração de faces (GOFFMAN, 1980) demonstraram a multifuncionalidade dos diminutivos. Enquanto os diminutivos do corpus carioca aparecem majoritariamente com funções pragmáticas, o que há no corpus madrileno é o predomínio do uso diminutivo indicando dimensão.

Palavras-chave: Diminutivos; Morfopragmática; Trabalho de face.

\footnotetext{
${ }^{1}$ Este artigo é uma versão atualizada da dissertação de mestrado de Camilla Santero (2011), intitulada "O uso do diminutivo em uma interação face a face: Análise comparativa em corpora orais das variantes madrilena e carioca".

2 Endereço eletrônico: camillasantero_6@hotmail.com
} 
Abstract: This descriptive-comparative work aims to identify the morphopragmatic functions of the diminutives in the sociolinguistic interview activity and observe whether the diminutive formations are at the service of the interviewee's facework, in order to confront their uses in the carioca variety of Portuguese and in the madrilena variety of Spanish. For this purpose, twelve interviews were analyzed, six from the NURC-RJ project and six from the PRESEEA project. The data analyzed was grounded on Morphopragmatics (DRESSLER; MERLINI BARBARESI, 2020) and on the Theory of Facework (GOFFMAN, 1980). The results revealed the multifunctionality of the diminutives. While the pragmatic functions prevail in the diminutives of the carioca corpus, the madrilena corpus display a predominance of diminutive use indicating dimension.

Keywords: Diminutives; Morphopragmatic; Facework.

\section{INTRODUÇÃO}

A literatura sobre os diminutivos tem contemplado tradicionalmente uma questão mais morfológica e semântica que morfopragmática.Em geral, os estudos que apresentam uma diferenciação entre os usos referenciais e subjetivos não vão além do que prevê a semântica. Atualmente, o que se assinala sobre os diminutivos é que muitas vezes funcionam como minimizadores (atenuantes) e que, tanto em português quanto em espanhol, nem sempre aparecem com valor de dimensão podendo associar-se a conotações afetivas, irônicas e até mesmo realizações cristalizadas (lexicalizações). No entanto ainda há muito por dizer sobre esse fenômeno de variação morfopragmática. Segundo Dressler e Merlini Barbaresi (2020), o poder explicativo da pragmática não é suficientemente explorado para dar conta dos complexos significados e efeitos transmitidos por certas operações morfológicas, principalmente no âmbito da formação de palavras, como os diminutivos.

No que se refere à abordagem dos diminutivos para o português brasileiro, Gonçalves (2007) salienta que as variações formais do grau diminutivo são as mais controversas na literatura linguística sobre o português, pois as abordagens não se mostram coerentes tanto na sua categorização como processo morfológico quanto na determinação dos significados que veiculam. 
No que concerne à língua espanhola, além da ideia de redução de tamanho, os sufixos são frequentemente associados a uma conotação afetiva, bem como a possibilidade de o diminutivo vir associado a um valor depreciativo. Não obstante, tais caracterizações são apresentadas como fixas e isoladas, ou seja, como se cada sufixo diminutivo carregasse um valor intrínseco, o que se desconstrói na prática linguística.

As gramáticas de ambas as línguas consideram os valores afetivos, pejorativos, apreciativos etc., como secundários. Contrariamente à atenção que as gramáticas normativas dão a esses valores dos diminutivos, os falantes de ambos os sistemas não só usam tais formações nas mais variadas situações, como também as relacionam a outros valores que não a mera diminuição daquilo a que se referem. Ao analisar a função que os diminutivos assumem em uma atividade ${ }^{3}$ de entrevista sociolinguística, pretendemos demonstrar a produtividade desse recurso morfopragmático que, de acordo com Dressler e Merlini Barbaresi (2020), não tem como escopo de influência a palavra, mas o ato de fala, colorindo toda a interação com seus efeitos pragmáticos.

Tanto em espanhol como em português, o diminutivo é um marcador pragmático altamente flexível e, em muitos contextos, com força de polidez em interações face a face. A realização diminutiva em ambos os sistemas apresenta um condicionamento pragmático ao revelar-se cultural e situacionalmente determinado. Para Brown e Levinson (1987), os diminutivos funcionam como estratégia da polidez linguística porque atenuam, mitigam um ato de ameaça.

\footnotetext{
${ }^{3} \mathrm{O}$ termo "atividade" é entendido neste trabalho como qualquer atividade socialmente constituída e culturalmente reconhecida, orientada para uma meta. Segundo Sarangi (2000), o tipo de atividade caracteriza o encontro social; para Levinson (1992), um tipo de atividade determina, em parte, o papel da linguagem em termos de estratégias ou procedimentos cabíveis; por exemplo, as perguntas feitas dentro da atividade entrevista sociolinguística, possuem especificidades moldadas pela própria atividade, ou seja, as interpretações são balizadas pelo tipo de atividade.
} 
Em uma entrevista sociolinguística, os diminutivos não são apenas um atenuador de atos de ameaça (uma estratégia de polidez), mas também um recurso a serviço do trabalho de construção de face (GOFFMAN, 1980), relacionado ao ethos interacional do falante. Portanto, uma análise pragmática dos diminutivos permite não só descrever o uso que os falantes fazem dos diminutivos, mas também reconhecer traços característicos de suas variedades.

Além do(s) significado(s) que possa(m) ser atribuído(s) aos morfemas diminutivos, o uso dessa marcação também indica um tipo especial de relação que o falante estabelece com o mundo ao seu redor, com seu(s) interlocutor(es) e com a entidade diminuída. Por esse motivo é importante estudar os diminutivos a partir das realizações do falante, observando em que situações de uso e com que finalidade esses afixos aparecem nas entrevistas sociolinguísticas.Afinal, as formas diminutivas podem funcionar como mecanismos de dêixis social, desempenhando um papel importante para marcar e construir as relações interpessoais; isto porque tais formas podem constituir a codificação linguística dos papeis sociais dos interactantes e da relação que existe entre eles, revelando muitas vezes as hierarquias sociais de uma dada comunidade.

É com base nesses fatos que este estudo descritivo-comparativo visa analisar como a dimensão pragmática dos diminutivos emerge em entrevistas sociolinguísticas em português e em espanhol, e até que ponto os usos convergem.

Consideramos apenas o sufixo -inho/a para o português e os sufixos -ito/a e -illo/a para o espanhol dado que, de um ponto de vista sincrônico, esses são os sufixos diminutivos mais produtivos nas variedades carioca e madrilena, conforme Beinhauer (1985), Alonso (1967), Koike (1992) e Soler Espianuba (1996), além de serem os mais frequentes nas entrevistas. 
A pesquisa justifica-se por faltarem estudos morfopragmáticos de base comparativa que possam contribuir para um maior conhecimento sobre como os diminutivos funcionam em variedades linguísticas do português e espanhol, com respeito aos seus usos e valores, principalmente porque investigamos somente as formações de base substantiva concreta, o que permitirá uma contraposição entre os usos subjetivos e referenciais.

Acreditamos que os diminutivos, cuja base é um substantivo concreto, são um mecanismo de derivação que funciona pragmaticamente como pista contextual (GUMPERZ, 2002) dos interlocutores na construção de face ${ }^{4}$ nas variedades carioca do português e madrilena do espanhol. Tendo em vista que tanto o falante do espanhol como o do português podem usar os diminutivos sintéticos para referirem-se à dimensão da entidade e/ou à valoração de sua subjetividade (REYNOSO NOVERÓN, 2005), o estudo tem por objetivo analisar e comparar os usos referenciais e subjetivos da formação diminutiva em ambas as variedades, para saber como funcionam dentro de uma interação e se estão a serviço da elaboração de face dos participantes.

O trabalho está dividido em três partes, além da introdução e das considerações finais. Na seção 1, apresentamos nosso quadro teórico, a saber, a morfopragmática e a teoria do trabalho de face. Na seção 2, explicamos a metodologia utilizada. Na seção 3, apresentamos a análise e discussão dos dados e encerramos com as considerações finais.

\section{MARCO TEÓRICO}

Nesta seção, apresentamos o marco teórico em que nos pautamos para fundamentar nossa reflexão e discussão acerca dos diminutivos que aparecem

\footnotetext{
${ }^{4}$ Face é um atributo social constantemente negociado no fluxo dos eventos de um encontro específico, que só se torna manifesto quando estes eventos são interpretados a partir das avaliações que neles se expressam (GOFFMAN, 1980).
} 
nas entrevistas sociolinguísticas. Para tanto, debruçamo-nos sobre a morfopragmática dos diminutivos e consideramos as questões interacionais que envolvem o trabalho de elaboração de face.

\subsection{A MORFOPRAGMÁTICA DOS DIMINUTIVOS}

Em seu ensaio sobre a expressão afetiva no espanhol coloquial, Beinhauer (1985) afirma que os sufixos diminutivos são o quebra cabeça de todas as gramáticas e métodos do espanhol. Após listar os sufixos diminutivos do espanhol presentes nas gramáticas normativas, incluindo os sufixos depreciativos e os regionais, o autor discute cada um deles e propõe analisar os sufixos -ito e -illo por serem os mais frequentemente utilizados com função diminutiva. Ainda segundo Beinhauer (1985), o sufixo -illo, além da função dimensional, pode assumir um valor subjetivo (pobrecillo $=$ digno de compaixão).

Para Alonso (1967) o sufixo -illo parece ser mais usado por classes sociais de menos prestígio enquanto -ito é preferido pelas classes mais prestigiadas; contudo, revela não haver uma definição tão rígida quanto às classes ou valores que cada sufixo representa. De acordo com o autor, o sufixo -illo ora funciona como expressão de afeto negativo, ora como afeto positivo, e conclui que o que vai determinar a função que cada sufixo assume é o falante e sua subjetividade, refletindo a tensão existente entre o sujeito e o objeto. Em consonância com Alonso (1967), acrescentamos que não há qualquer significação atribuída

permanentemente aos sufixos diminutivos. É o falante que, em um determinado contexto, vai significar o morfema segundo seu objetivo comunicativo.

No que se refere à Língua Portuguesa, as gramáticas normativas apresentam suas listas com os sufixos diminutivos e não vão além de uma 
classificação estrutural que contrapõe as formas sintéticas (base + afixo = casinha) às analíticas (construções sintáticas como casa pequena). Algumas gramáticas (ROCHA LIMA, 2006; BECHARA, 2005) destacam o fato de os afixos diminutivos não expressarem unicamente tamanho, no entanto, não detalham essa afirmação, apresentando os outros possíveis usos do sufixo diminutivo.

Para Rocha (1998), a afetividade está sempre presente na sufixação gradual, porém a ideia de diminuição pode estar presente ou não, como o caso de timinho que tende a veicular conteúdos pejorativos. Loures (2000) também destaca a função afetiva como particular valor subjetivo dos sufixos diminutivos, não expressando necessariamente a sua dimensão, mas a afetividade, positiva (p.ex. cachorrinho) ou negativa (p.ex. leizinha), do falante.

Em outras palavras, os morfólogos veem como a principal função dos afixos diminutivos a de realçar qualidade e/ou quantidade, segundo os padrões individuais e subjetivos do falante. As pesquisas linguísticas indicam que os diminutivos apresentam função atitudinal e, por isso, tendem a atuar na interface morfologia-pragmática (DRESSLER; MERLINI BARBARESI, 2020). Desse modo, Gonçalves (2007, p.165) afirma que os diminutivos:

[...] dependem de fatores como (a) o nível de envolvimento entre falante e ouvinte; (b) os propósitos comunicativos do emissor diante da audiência; e (c) o grau de formalidade do discurso. Dependentes da situação comunicativa, os significados dos afixos de grau, utilizando as palavras de Levinson (1983, p.23) “são negociáveis na transação conversacional.

Alonso (1967) também ressalta o caráter predominantemente afetivo dos afixos diminutivos em espanhol, que se dá através da representação afetivoimaginativa do objeto, ou seja, não é tanto uma relação entre significado e significante, mas é o juízo de valor do falante sobre o objeto referido. A nosso ver, o juízo de valor do falante não recai apenas sobre o objeto, mas sobre todos os constituintes do evento de fala, no qual ele é participante. 
Segundo o autor, quando o sentido central é realmente diminuição, a ideia de redução de tamanho se faz por outros recursos. Em outras palavras, o papel desses sufixos é especializar o dito. Alonso (1967) desenvolve seu argumento a favor da preponderância das representações da fantasia que, para ele, está intimamente ligada à emoção, através do afeto e da valorização do objeto.

Embora o autor em questão não reconheça os sufixos diminutivos como um recurso pragmático em potencial, ele deu início a uma trajetória que parecia caminhar para a descoberta da função dos diminutivos numa troca interpessoal. De acordo com ele, os diminutivos deveriam ser analisados considerando os elementos contextuais e acrescenta que é preciso superar a ideia de que a noção afetiva tem origem na ideia reducional que lhe é atribuída.

Seguindo essa mesma linha de raciocínio, Dressler e Merlini Barbaresi (2020, p.406), ao analisarem a sentença "Como eu adoraria estar na minha caminha." 5 , afirmam que o significado semântico de tamanho pequeno não pode ser a razão de tal ocorrência, mas é a coloração emocional do ato de fala que aciona a imaginação da cama desejada. De acordo com os autores, além do recurso semântico de pequenez para os diminutivos, há o recurso pragmático [+ fictício], especificado pela característica (não-sério). Tal característica não se limita apenas ao discurso centrado na criança ou na fala infantilizada, mas se estende às situações de fala que envolvam intimidade, familiaridade, simpatia, empatia, alegria, etc., além dos casos em que o diminutivo é usado para diminuir a responsabilidade do falante com o dito. A relação entre o traço semântico de pequenez e o recurso pragmático (não-sério) pode gerar confusões, como a constante associação das formações diminutivas ao infantil.

Para Dressler e Merlini Barbaresi (2020), os padrões de formação de palavras podem ter um significado pragmático básico, ou pelo menos gerar

\footnotetext{
5 "How I'd love to be in my bed-DIM" (DRESSLER; MERLINI BARBARESI, 2020, p.406)
} 
efeitos pragmáticos secundários, tendo como base um significado semântico referencial. Mais precisamente, a morfopragmática se refere a uma regra morfológica que contém uma variável pragmática que não pode ser suprimida na descrição de seu significado.

Segundo os autores, se os aspectos sociais da morfologia derivacional não fossem negligenciados, a superioridade da pragmática sobre a semântica na morfologia seria mais perceptível. Em defesa desse argumento, eles se valem, por exemplo, do processo de aquisição de L1, no qual as crianças adquirem primeiro os usos morfopragmáticos e posteriormente os morfossemânticos.

Quando a formação diminutiva extrapola a relação com a palavra base, já não se trata de morfossemântica, mas morfopragmática.Segundo Briz (2005), uma análise (morfo)pragmática considera, além do conteúdo comunicado, um falante que comunica e que manifesta uma atitude diante do comunicado, e um ouvinte que interpreta o codificado em determinadas circunstâncias comunicativas. Ao definir os estudos pragmalinguísticos como centrados na investigação das formas linguísticas - entendidas como estratégias adequadas para se alcançar uma meta, o autor ressalta que os morfemas diminutivos são uma forma linguística que pode funcionar como pista contextual em uma atividade específica.

Consoante com Briz (2005), Dressler e Merlini Barbaresi (2020) salientam que uma análise (morfo) pragmática não repousa apenas no complexo trabalho inferencial do linguista, mas na identificação das motivações cotextuais e contextuais, bem como nas reações perlocucionárias, reconhecendo pistas contextuais e índices linguísticos relevantes. 


\subsection{OS DIMINUTIVOS EM UMA INTERAÇÃO SOCIAL}

Nesta seção, apresentamos uma breve explanação dos conceitos que envolvem o trabalho de face e dão suporte teórico à análise dos diminutivos que aparecem nas entrevistas.

A seguir, discorremos algumas linhas sobre as contribuições de Goffman (2009), Brown e Levinson (1987) e seus contemporâneos (TERKOURAFI, 2005; MILLS, 2011; SPENCER-OATEY, 2007; BRAVO, 2005, BRIZ, 2005), no que se refere ao funcionamento dos diminutivos em encontros comunicativos.

O uso do morfema diminutivo é pragmaticamente relevante, porque ao expressar julgamentos é seguido, normalmente, pela aprovação ou rejeição do interactante. Logo, enunciar juízos de valor envolve certo risco, de ter sua opinião confirmada ou não pelo interlocutor e, consequentemente, implica o trabalho de face (GOFFMAN, 1980).

Segundo Tannen e Wallat (2002), numa interação cada interlocutor traz um esquema de conhecimento, ou seja, uma expectativa acerca das pessoas, objetos, eventos e demais elementos envolvidos na troca comunicativa, bem como as informações buscadas ao longo desse processo. Quando informados a respeito de seu interactante, escolhem o que julgam ser o melhor modo de interagir para atingirem qualquer que seja seu objetivo comunicativo. Nesse pormenor, Goffman (2009) argumenta que,

quando um indivíduo desempenha um papel, implicitamente solicita a seus observadores que levem a sério a impressão sustentada perante eles. Pede-lhes para acreditarem que o personagem que veem no momento possui os atributos que aparenta possuir, que o papel que representa terá as consequências implicitamente pretendidas por ele, e que, de um modo geral, as coisas são o que parecem ser. (GOFFMAN, 2009, p.25)

Para Goffman (1980), optar por um comportamento em dada interação significa adotar uma linha, ou um padrão, de atos verbais e não verbais para 
opinar sobre a situação, submetendo o outro e a si próprio à avaliação. Essa linha afeta o outro que, por seu turno, atribuirá ao interlocutor uma imagem pública, uma face coerente com o que ele presume ser a linha tomada por seu interlocutor.

Conforme Brown e Levinson (1987) a face implica um empenho emocional - podendo ser perdida, mantida ou enaltecida - e deve ser preservada durante a interação. Em geral, as pessoas cooperam para a manutenção das faces durante uma interação. Esta cooperação está baseada na mútua vulnerabilidade das faces.

Desse modo, o trabalho de face envolve ações realizadas para sustentar a face. Mantê-la implica ter adotado uma linha coerente com a anterior e perdê-la significa não conseguir integrar à face que estava sendo sustentada a nova informação sobre seu valor social. Se há interação, há trabalho de face, seja para construir a imagem pública do falante - como ele quer ser visto por seu(s) interlocutor(s), seja para não perder a face diante de um possível ato ameaçador.

Sobre a ameaça à face, caracteriza-se como tal, todo o ato que viole os desejos básicos dos participantes de dada interação. O que Brown e Levinson (1987) chamam de desejo da face negativa, se aproxima do que Bravo (2005) denomina desejo de autonomia e Spencer-Oatey (2007) classifica como direito à equidade, ou seja, o desejo de não receber imposições e ter liberdade de ação. Já o desejo da face positiva ou desejo de afiliação, trata-se do desejo de ser aceito pelo interlocutor, sentindo-se parte do grupo com o qual interage.

Nesse constante exercício de atender aos desejos da própria face e, com alguma frequência, aos desejos da face de seu interlocutor, os participantes de uma interação interpretam todas as variáveis que incidem sobre o contexto em que a troca comunicativa se dá. Muitas informações são explicitadas por diferentes elementos verbais, não-verbais, paraverbais, etc, servindo à polidez 
ou a outro aspecto que atue na construção de face do interlocutor. Os diminutivos são elementos verbais que podem funcionar como pistas de contextualização (GUMPERZ, 2002), sinalizando pressuposições contextuais que influirão na interpretação do interlocutor.

As pistas contextuais, como os diminutivos por exemplo, só assumem significação dentro de um contexto. Ou seja, um diminutivo pode funcionar como marca de afetividade e informalidade interpessoal em uma conversa entre amigos, mas a mesma formação pode desempenhar a função de um atenuante em outro contexto. As pistas de contextualização são coerentes com o alinhamento tomado pelo falante em sua relação com o outro.

\subsubsection{A ATENUAÇÃO}

A atenuação como uma estratégia conversacional distancia o falante da mensagem e pode aproximá-lo de seu interlocutor. De acordo com Briz (2005), a atenuação como uma categoria pragmalinguística reduz o benefício de quem fala, reduz sua contribuição e, consequentemente, um possível desacordo que possa impedir o êxito comunicativo. O fato de evitar desacordos está associado ao trabalho de elaboração de face, porém, não necessariamente à polidez. A atenuação, portanto, está ligada à eficácia e eficiência pragmáticas, tendo uma relação muito maior com a face que com a polidez propriamente dita.

A atenuação pragmalinguística retrata uma tentativa de se salvaguardar as faces de ambos os participantes da interação, buscando um equilíbrio estratégico que envolva, ou não, a polidez. O principal objetivo da atenuação é a minimização da força ilocucional em prol do prosseguimento da interação sem maiores tensões (BRIZ, 2005).

O diminutivo que funciona como um atenuante reforça a argumentação do falante, de modo a convencer seu interlocutor, pois aumenta a eficácia e 
eficiência da mensagem. No entanto, em algumas situações a eficácia linguística depende da eficácia social, implicando uma atividade atenuadora estrategicamente polida (BRIZ, 2005). Segundo o autor, a maior ou menor presença de atenuantes em uma interação é proporcional ao grau de desacordo existente na troca comunicativa, o que justifica a baixa incidência de diminutivos com função atenuadora nas entrevistas sociolinguísticas analisadas.

\subsubsection{A POLIDEZ}

Os contemporâneos de Brown e Levinson (1987), como Terkourafi (2005), Mills (2011), Bravo (2005), Briz (2005) e Spencer-Oatey (2007), argumentam que não há um padrão do que é mais polido ou menos polido. A polidez ganha um caráter dinâmico e situado. O falante será polido ou rude dependendo menos do que ele diz, e mais da avaliação feita por seu interlocutor. A polidez ou cortesia é tida como um julgamento social no qual as elocuções são meras aberturas para a interpretação da mesma.

Para Terkourafi (2005), a polidez não é um cálculo racional de atenuação à ameaça da face como consideravam Brown e Levinson (1987), mas é habitus ${ }^{6}$ (esquema de conhecimentos que orienta sua prática) e frame (estruturas de dados de uma base de conhecimentos para a representação de situações estereotipadas).

Sobre o conceito de polidez, têm-se, na atualidade, diferentes sentidos e funções para o mesmo em diferentes culturas. Os pós Brown e Levinson, como Mills (2011) e Terkourafi (2005), não focam a polidez no nível da frase ou sentença e não assumem que a polidez seja inerente à palavra usada na

\footnotetext{
6 A noção de habitus, retomada de Bourdieu (1983 apud HANKS, 2008), significa as disposições que geram as práticas, as percepções e atitudes sendo frequentes, porém não conscientes. Este set de atitudes ou práticas constitui as normas negociadas pelos indivíduos.
} 
interação - o foco está no contexto, nas forças sociais, no discurso propriamente dito. Não existe nenhuma conceitualização antes ou depois do discurso. O indivíduo negocia as normas sociais ao mesmo tempo em que é formado por elas.

O modelo construído por Brown e Levinson (1987) trata o conceito de face como uma categoria pré-concebida, já os pós modernos, incluindo SpencerOatey (2007), encaram a face como um construto dinâmico e negociado na interação. A autora acredita, assim como Brown e Levinson (1987), que o conceito de face é universal. No entanto, reconhece que as diferenças culturais afetam, por exemplo, a escolha da estratégia mais apropriada para o trabalho de face.

A pragmática como o uso da língua em contexto estuda a configuração das relações sociais através da língua. E a polidez na interação face a face define e constrói a relação social entre os participantes recorrendo às convenções que fazem parte do contexto sociocultural, o qual não é necessariamente compartilhado em outras comunidades, podendo gerar mal-entendidos interculturais. Desse modo a polidez linguística é objeto de interesse para a pragmática posto que trata das relações entre língua, cultura e sociedade.

Conforme Goffman (2009) e Brown e Levinson (1987), qualquer participante de uma interação tem desejos de face, ou seja, deseja ser respeitado e reconhecido e, para isso, recorre ao comportamento socialmente aprovado pelos integrantes do grupo do qual faz parte através de ações verbais e nãoverbais, dentre estas a polidez, que também é um tipo de trabalho de face.

O trabalho de face realizado durante uma interação pode funcionar como polido, quando realizado pelo falante em prol de seu interlocutor. Entretanto, a polidez não dá conta de todas as possibilidades de trabalho de face (HERNÁNDEZ FLORES, 2004), afinal há casos em que o trabalho de face 
realizado pelo falante é voltado a sua própria imagem, não porque se sinta ameaçado, mas porque necessitamos construir e manter a face na interação.

Na próxima seção, expomos a metodologia utilizada para analisar os diminutivos que aparecem nas entrevistas sociolinguísticas.

\section{METODOLOGIA}

Nesta seção exibimos os pressupostos metodológicos que possibilitaram a análise qualitativa dos diminutivos coletados nos corpora. Apresentamos a fonte dos dados, a seleção dos sufixos diminutivos, a atividade entrevista sociolinguística, as ferramentas de análise construídas a partir da junção de métodos utilizados por outros pesquisadores que exploraram os sufixos diminutivos e o ethos das comunidades envolvidas.

Para a análise deste trabalho, foi feito um levantamento das 42 ocorrências de formações diminutivas de sufixo -illo, -ito e -inho, cuja base é um substantivo concreto, em doze entrevistas sociolinguísticas realizadas na década de 90 .

Abaixo apresentamos os dados quantificados:

Quadro 1- Dados dos corpora quantificados que deram origem as 42 ocorrências de formação diminutivas.

\begin{tabular}{|l|l|}
\hline \multicolumn{1}{|c|}{$\begin{array}{c}\text { Dados quantificados } \\
\text { (corpus carioca) }\end{array}$} & \multicolumn{1}{c|}{$\begin{array}{c}\text { Dados quantificados } \\
\text { (corpus madrileno) }\end{array}$} \\
\hline Total de palavras: $\mathbf{2 2 . 2 3 9}$ & Total de palavras: $\mathbf{4 8 . 8 8 9}$ \\
Total de diminutivos:41 & Total de diminutivos: $\mathbf{8 7}$ \\
Total de diminutivos analisáveis: $\mathbf{1 7}$ & Total de diminutivos analisáveis: $\mathbf{2 5}$ \\
Frequência Relativa: $\mathbf{4 1 \%}$ diminutivos de & Frequência Relativa: $\mathbf{2 8 \%}$ diminutivos de \\
base substantiva concreta. & base substantiva concreta \\
\hline
\end{tabular}


Das doze entrevistas selecionadas, seis são do projeto PRESEEA (Projeto para o Estudo Sociolinguístico do Espanhol da Espanha e da América) de Alcalá de Henares - Espanha, e seis do projeto NURC-RJ (Projeto da Norma Linguística Urbana Culta) - Brasil. Em cada variedade foram analisados três homens entre 28 e 33 anos e três mulheres entre 23 e 31 anos, todos com ensino superior completo. A escolha das variedades madrilena e carioca deve-se ao fato de o Rio de Janeiro e Alcalá de Henares terem um papel importante no modelo normativo.

O projeto PRESEEA foi compilado em 1998 para contribuir com estudos comparativos entre as cidades hispano-falantes do mundo. As províncias que são membros da comunidade autônoma de Madrid possuem uma vida socioeconômica totalmente articulada à capital hegemônica - Madrid. A variedade linguística de Alcalá de Henares está vinculada à norma culta de Madrid, que orienta os usos dos falantes desse território.

O NURC foi criado em 1992 para construir um banco de dados de oralidade urbana culta de cinco capitais brasileiras, dentre elas o Rio de Janeiro. As entrevistas em ambos os projetos versam sobre família, trabalho e cidade, e foram criados por motivos outros de investigação, que não os diminutivos.

No que se refere à atividade entrevista sociolinguística, entendemos por atividade toda situação comunicativa socialmente constituída e culturalmente reconhecida, orientada para uma meta, podendo envolver diferentes graus de padronização (LEVINSON,1992). Os graus de padronização estão relacionados aos tipos de contribuições permitidos como participantes, local, duração da atividade, o que é dito e como é dito, etc.

Segundo Briz (2005), a entrevista é um discurso (a) oral, uma modalidade produzida e recebida pelo canal fônico, (b) dialogal, devido a sucessão de turnos, (c) imediata, já que se desenvolve na coordenada espaço-temporal do 
aqui e agora, (d) cooperativa, porque é co-construída e (e) dinâmica, pela contínua mudança de papeis entre os interlocutores (ora um interlocutor é falante, ora é ouvinte). No entanto, para Briz (2005) e Kerbrat-Orechioni (2005) a entrevista não pode ser considerada uma conversa, porque, dentre outros fatores, possui certo controle na alternância de turnos.

Portanto os resultados desta pesquisa informam sobre a função pragmática dos diminutivos em uma entrevista semiformal com tópicos préestabelecidos.

\subsection{UMA CATEGORIZAÇÃO MORFOPRAGMÁTICA}

As formações diminutivas se encontram em um continuum funcional que vai do polo referencial ao subjetivo, tendo no meio deste trajeto sobreposições de funções, ou seja, podemos encontrar diminutivos que, ao mesmo tempo em que apresentam uma ideia dimensional, também contribuem para a expressão da subjetividade do falante, interferindo assim na interação com seu interlocutor. Tendo em vista que o uso subjetivo de uma formação diminutiva provoca uma reação no ouvinte que vai além do enunciado, podemos afirmar que a semântica está a serviço da pragmática.

Os sufixos derivacionais selecionados são -illo e -ito do espanhol e -inho do português, para contrapor a função referencial à subjetiva nas formações de base substantiva concreta.

Para os fins desta pesquisa, observamos em que estágio de lexicalização se encontram as formas diminutivas selecionadas e consideramos em estágio avançado de lexicalização as formações que não são mais sentidas coletivamente como derivações, embora possuam base livre e o autêntico sufixo. Essas formações não são intercambiáveis com o grau normal. Em estágio médio de lexicalização estão as formações que ainda se alternam com o grau 
normal, sendo interpretadas ora como derivadas, ora como não derivadas por diversos falantes em diferentes contextos (ex. nego versus neguinho). Por último estão as formações em estágio baixo de lexicalização sentidas como derivações reais. Neste trabalho investigamos somente as ocorrências em estágio médio e baixo de lexicalização.

A categorização construída a partir dos modelos de análise de Ezarani (1989) e Turunem (2009) ganhou forma após a observação dos dados nos corpora. O modelo contextual para a análise morfopragmática compreende em um polo o uso referencial - interpretado como "X é pequeno" - e no extremo oposto os usos subjetivos. O polo subjetivo se divide entre os usos afetivo positivo - que estabelece uma relação de afetividade com seu referente, afetivo negativo - que marca uma relação de insatisfação, de crítica, e de pejoratividade no que diz respeito a seu referente, e de atenuação - que se refere exclusivamente à relação com o interlocutor, podendo ser interpretado como uma aproximação social e/ou um distanciamento linguístico. Este recurso pode favorecer a face do falante ou ambas as faces envolvidas na interação.

No que se refere à análise do co-texto, os critérios desenvolvidos por Ezarani (1989) fornecem subsídios à análise contextual de uma determinada ocorrência diminutiva a partir dos elementos circundantes. Os critérios cotextuais especificados a seguir favorecem a classificação de uma ocorrência com função referencial (dimensional): (1) o referente da palavra base é passível de redução de tamanho; (2) há possibilidade de substituição da forma sintética pela analítica; (3) há possibilidade de co-ocorrência do adjetivo pequeno com a forma diminutiva e (4) o referente da palavra base traz em si a ideia de pequenez.

Os critérios co-textuais que contribuem para a definição de uma ocorrência como de afeto positivo são: (1) o referente da palavra base não é passível de redução em termos concretos; (2) presença de referenciadores de 
primeira pessoa; (3) presença de estruturas reiteradoras de apreciação positiva e (4) repetição do objeto de afeto.

No que concerne aos critérios co-textuais que favorecem a interpretação de uma ocorrência como sendo de afeto negativo: (1) o referente da palavra base não é passível de redução em termos concretos; (2) presença de dêiticos de segunda e terceira pessoas; (3) presença de indefinidor acompanhado de dêiticos e (4) presença de estruturas reiteradoras da pejoratividade.

Baseados nas teorias que exploram o conceito de trabalho de face, buscamos corroborar duas noções, a da função pragmática como inerente a toda interação e a dos usos diminutivos a serviço da construção de face, traçando um paralelo quanto ao uso dos mesmos nas duas variedades em questão.

Em todos os 42 dados buscamos identificar as causas promotoras das formações diminutivas, atentando para o contexto e o co-texto transcritos em cada entrevista, além do conhecimento do ethos de cada comunidade de fala.

\subsection{O ETHOS DAS VARIEDADES MADRILENA E CARIOCA}

Os participantes de uma dada interação refletem a cultura da qual são membros. As especificidades de cada cultura influenciam diretamente na análise dos dados, afinal a escolha por uma formação diminutiva diz muito sobre aquela comunidade de fala, se é uma cultura de ethos + afiliativo ou não, por exemplo.

Perfil comunicativo ou o ethos é como Kerbrat-Orecchioni (2005) denomina a maneira de um falante se comportar no discurso para alcançar seu objetivo. É a maneira de se apresentar na interação - mais ou menos calorosa ou fria, mais ou menos próxima etc. Segundo essa autora, outros autores definem o ethos como um estilo comunicativo ou conversacional. Buscando uma tipologia das sociedades, ela contrapõe os seguintes elementos: a) Povos menos 
comunicativos $x$ sociedades mais falantes, $b$ ) ethos de proximidade $x$ ethos de distância, c) ethos hierárquico x igualitário, d) ethos consensual x conflituoso e e) sociedades mais ritualizadas $\mathrm{x}$ menos ritualizadas.

Retomando o conceito de face (imagem social), Bravo (2005) lança duas categorias vazias de face que tomam forma em cada cultura de acordo com o conhecimento compartilhado entre os participantes de cada sociedade. São elas os desejos de autonomia e afiliação: o primeiro, alude ao fato de que a pessoa quer ser reconhecida individualmente em meio ao grupo; o segundo, refere-se a tudo aquilo que a permite identificar-se como pertencente ao grupo.

Segundo a autora, os conceitos de afiliação e autonomia coincidem parcialmente com as noções de imagem positiva e negativa, considerando a sociedade espanhola, e acrescentamos a brasileira, onde a autonomia é menos vista como um desejo de não ser "invadido", e mais vista como um desejo de ser original e assim diferenciar-se do grupo. Em relação aos espanhois, a autora pontua as seguintes premissas culturais: i) é valorizado aquele que é original e consciente das próprias qualidades; ii) a imagem que o indivíduo tem de si mesmo e o apreço dos outros confirmam suas qualidades positivas; iii) tolera-se a expressão de opiniões; iv) realizam-se grandes esforços para comprometer-se com o dito: isso supõe um poder de convencimento sobre seu interlocutor; v) os conflitos não implicam comprometimento da relação social, pelo contrário, muitas vezes contribuem fortalecendo o laço interpessoal e vi) a relação social se estabelece por graus de confiança. Em função dessa confiança, existem situações em que se pode falar sem temer a ofensa.

Hernández Flores (2002) argumenta que o desejo de autonomia dos espanhóis está relacionado à expressão da autoafirmação, mostrando-se original e consciente de suas qualidades. Sobre o desejo de afiliação, ela menciona o ideal de confiança. A imagem de autonomia espanhola pode ser vista na firmeza e no caráter persuasivo com que expressam suas opiniões 
carregadas de emoção. Já a de afiliação, marca uma proximidade, um tom mais familiar ao que é dito. Segundo Bravo (2005), a autoafirmação pode causar conflitos, ainda que seja condição para obter apreço, pois ao mesmo tempo em que enfatiza as qualidades do eu, pode ir de encontro ao eu do interlocutor.

A autoafirmação é um valor socialmente aprovado na cultura espanhola, como se observa na tolerância por opiniões contrárias à defendida pelo falante. Outro valor aprovado é a confiança - relacionada à autoafirmação, afinal, quando o falante se afirma é porque tem confiança no grupo ao qual se dirige, e este por sua vez, renova a confiança no falante mediante sua autoafirmação (Bravo, 2005).

A seguir propomos um quadro comparativo entre o ethos espanhol e o brasileiro, que serviu como instrumento de análise no tratamento dos dados da variedade madrilena e carioca, respectivamente. 
Quadro 2- Proposta comparativa de ethos nas variedades analisadas.

\begin{tabular}{|c|c|}
\hline Espanha & Brasil \\
\hline + valorizado aquele que é original. & + valorizado aquele que é original. \\
\hline $\begin{array}{l}+ \text { valorizado aquele que se mostra } \\
\text { consciente das próprias qualidades. }\end{array}$ & $\begin{array}{l}\text { - valorizado aquele que se mostra } \\
\text { consciente das próprias qualidades }{ }^{7} \text {. }\end{array}$ \\
\hline $\begin{array}{l}\text { A imagem que o indivíduo tem de si } \\
\text { mesmo e o apreço dos outros confirmam } \\
\text { suas qualidades positivas. }\end{array}$ & $\begin{array}{l}\text { A imagem que o indivíduo tem de si não } \\
\text { confirma suas qualidades positivas, } \\
\text { apenas o apreço alheio pode fazê-lo. }\end{array}$ \\
\hline $\begin{array}{l}+ \text { valorizada a expressão direta de } \\
\text { opiniões. }\end{array}$ & $\begin{array}{l}\text { - valorizada a expressão direta de } \\
\text { opiniões. }\end{array}$ \\
\hline + comprometimento com o dito. & - comprometimento com o dito. \\
\hline $\begin{array}{l}\text { Os conflitos não implicam } \\
\text { comprometimento da relação social. }\end{array}$ & $\begin{array}{l}\text { Os conflitos implicam comprometimento } \\
\text { da relação social. }\end{array}$ \\
\hline + confiança $=$ opinião contrária. & + confiança $\neq$ opinião contrária. \\
\hline + confronto & $+\mathrm{COI}$ \\
\hline
\end{tabular}

Fonte: Própria.

Em seu trabalho sobre o script cultural de simpatia, Triandis (1984) compara os hispano-americanos aos não hispânicos nos Estados Unidos e observa que a simpatia é o padrão de interação social que caracteriza os latinoamericanos como um todo. Segundo o autor, a simpatia é uma qualidade pessoal permanente. O indivíduo "simpático" é percebido como agradável, fácil de lidar, com habilidade para expressar sentimentos e conformidade.

Para Triandis (1984), o indivíduo que é simpático se comporta com dignidade, respeita os outros e contribui para a harmonia nas relações interpessoais, rejeitando o conflito e enfatizando comportamentos positivos. A rejeição a comportamentos negativos estaria baseada nos valores culturais

\footnotetext{
7 “+ valorizado aquele que embora consciente de suas próprias qualidades não se mostra como tal aos outros".
} 
latino-americanos como o respeito e a dignidade. Os comportamentos que são interpretados culturalmente como crítica ou insulto são percebidos pelos latinoamericanos como uma agressão, violação à dignidade do outro.

Nesse sentido, a cordialidade e a afabilidade emergem como uma importante característica no modelo de comportamento social dos latinoamericanos. A preferência pelas relações harmoniosas entre os hispanoamericanos e o "ser simpático", como um tratamento pessoal valorizado, constituem um importante passo na definição dos padrões preferidos pelos latinos em relações interpessoais.

A partir das considerações de Triandis (1984) para o grupo cultural dos latino-americanos, podemos esboçar um paralelo entre esse grupo e o grupo peninsular. Nesse caso, o "rótulo" de simpatia atribuído aos latino-americanos (e, porque não aos cariocas?), justificaria o uso mais frequente dos diminutivos para expressar afeto negativo, enquanto a comunidade madrilena o faria de forma direta por valorizar a crítica e a expressão de opiniões de uma forma geral.

Com os conceitos teóricos e as ferramentas de análise devidamente explicitados, passamos para a análise dos dados e discussão dos resultados.

\section{OS USOS DOS DIMINUTIVOS NOS CORPORA}

Por motivos de espaço, apresentamos no quadro abaixo apenas uma amostra dos resultados para cada uma das variedades investigadas. 
Quadro - 3 Amostra das funções diminutivas encontradas em cada variedade

\begin{tabular}{|c|c|c|}
\hline & Variedade Madrilena & Variedade Carioca \\
\hline Referencial & $\begin{array}{l}<1>\text { y luego pue:s// los trocitosde: } \\
\text { chorizo y de panceta me parece } \\
\text { que/ o se juntan o se separan// } \\
\text { depende// mi madre lo hace } \\
\text { separado// }\end{array}$ & $\begin{array}{l}<\text { loc }>E \text {, achei as cidades, assim, } \\
\text { legais. Conheci o lado francês, } \\
\text { né, de Montreal, ali, algumas } \\
\text { cidadezinhas, por ali, e o lado } \\
\text { inglês, também. }\end{array}$ \\
\hline $\begin{array}{l}\text { Afeto } \\
\text { Positivo }\end{array}$ & $\begin{array}{l}<2>(\mathrm{hm})(\mathrm{hm}) \text { ¿estás contenta? } \\
<1>\text { mientras siga en- en mi } \\
\text { pisito// (risa }=2) \text { estar contenta } \\
\text { con los muebles }\end{array}$ & $\begin{array}{l}<\text { loc }>\text { Às vezes tem o velhinho } \\
\text { que senta na praça e você já... E, } \\
\text { o velho vai encostar! Não sei o } \\
\text { quê, de repente o velho tem } \\
\text { uma cabeça super aberta, super } \\
\text { jovem. }\end{array}$ \\
\hline $\begin{array}{l}\text { Afeto } \\
\text { Negativo }\end{array}$ & $\begin{array}{l}\text { ¿qué fiestas son/las que hay allí?// } \\
<1>\text { pues allí son en verano// aquí } \\
\text { es en septiembre (lapso = 2) y las } \\
\text { fiestas es que duran me parece } \\
\text { que muchos días/ una semana o:// } \\
\text { más de una semana: y allí pues } \\
\text { eso/// (hh) lo que hay mucho es: la } \\
\text { vidilla ésta que le dan las peñas } \\
\text { (lapso = 2) entonces como la gente } \\
\text { allí se conoce: la mayoría// }\end{array}$ & $\begin{array}{l}<\text { loc>por exemplo eu vejo que, } \\
\text { eu na minha geração e tal, fui } \\
\text { muito mais livre do que essas } \\
\text { meninas, o que não quer dizer, } \\
\text { que isso seja uma regra, porque } \\
\text { tem umas meninas aqui, aqui na } \\
\text { rua mesmo que, com treze anos, } \\
\text { pô, tão de namoradinho firme, } \\
\text { sabe, pô, fumam maconha, } \\
\text { fazem o diabo, entendeu, e as } \\
\text { garotas são pequenas, eu olho e } \\
\text { fico assim: Meu Deus! }\end{array}$ \\
\hline Atenuação & $\begin{array}{l}<2>\text { ¿te gustaría segui:r historia de } \\
\text { la lengua o no? } \\
<1>\text { sí/// no es/ no lo sé/ son las dos } \\
\text { cosas/ sigo/ es que de hecho/ } \\
\text { sigo// ¿me entiendes?/ me gano la } \\
\text { vida con// esto pero:// algunas } \\
\text { cosillas sigo haciendo en historia } \\
\text { de la lengua// al menos transcribir } \\
\text { documentos// (uf:)// nada }\end{array}$ & $\begin{array}{l}<\text { loc }>\text { não... TER nunca tinha... } \\
\text { mas a gente sempre dava um } \\
\text { jeito de criar alguma coisa... } \\
\text { no... no mínimo ficava em casa } \\
\text { vendo televisão... comendo } \\
\text { pipoca... assistia até jogo na } \\
\text { televisão por falta do que fazer } \\
\text { na cidade né? mas sempre... } \\
\text { sempre se reunindo com } \\
\text { alguém ...eu ia pra casa de } \\
\text { alguém que tinha piscina... ou } \\
\text { totó... qualquer joguinho } \\
\text { mesmo... desses de } \\
\text { imaginação... ficar fazend isso... }\end{array}$ \\
\hline
\end{tabular}

Nenhuma das ocorrências de formação diminutiva no corpus das mulheres cariocas apareceu com função unicamente referencial. As formações 
diminutivas estiveram muito mais a serviço da subjetividade do falante que do uso meramente referencial. Dentro do polo subjetivo, a função mais frequente foi a de afeto negativo, o que demonstra por parte das entrevistadas um maior cuidado ao expressarem juízos de valores negativos.

O corpus dos homens cariocas revela baixa incidência de formações diminutivas de base substantiva concreta que não estejam em estágio avançado de lexicalização. Dos três entrevistados apenas o de 28 anos realizou uma formação diminutiva analisável, em estágio médio de lexicalização (derivação real) com função referencial.

Enquanto o uso de diminutivos de base substantiva no corpus dos homens cariocas foi quase nulo (mercadinho), no das mulheres mostrou-se bastante produtivo (16 ocorrências). Em todo o corpus carioca, só apareceu um uso atenuante (joguinho) e três referenciais (cidadezinhas, plantinhas e mercadinho), já os usos de afeto positivo (6 ocorrências) e negativo (8 ocorrências) tiveram resultados equilibrados e mais significativos em número.

No que se refere ao corpus madrileno, em meio a um total de 46 diminutivos, foram encontrados no corpus das mulheres dezesseis ocorrências analisáveis (4 referenciais, 5 com funções sobrepostas, 4 de afeto negativo, 3 de afeto positivo e 1 com função atenuante). Já no corpus dos homens, foram nove diminutivos analisáveis (3 usos referenciais, 2 usos com funções sobrepostas, 3 de afeto positivo e 1 atenuante) de um total de 40 diminutivos.

No corpus das mulheres madrilenas, encontramos 4 formações diminutivas que se situam no polo subjetivo e desempenham a função de afeto negativo, 5 ocorrências dizem sobre os usos com funções sobrepostas, estando todas entre o polo referencial e o subjetivo de afeto positivo.

No âmbito da atenuação temos somente duas ocorrências no corpus madrileno - o diminutivo "cosilla" em estágio baixo de lexicalização (derivação real). Tal formação apareceu em conversas sobre trabalho. 
No corpus das mulheres madrilenas, o uso referencial dos diminutivos é o mais frequente, ainda que seja sobreposto à função de afeto positivo. No polo subjetivo, se consideramos as formações com funções sobrepostas, os usos de afetivo positivo foram mais expressivos que os de afeto negativo. O ethos dessa comunidade reforça a baixa incidência de formações diminutivas com afeto negativo, afinal, sendo uma cultura mais diretiva, os diminutivos não são a forma preferida para expressar juízos de valor negativos. Tal recurso é mais produtivo em comunidades com um ethos menos diretivo, preferindo respostas mais evasivas por meio, entre outras coisas, das formações diminutivas.

Considerando os corpora masculinos de ambas as variedades, o corpus madrileno se revelou muito mais expressivo (nove ocorrências), no que diz respeito ao uso de diminutivos de base substantiva concreta, que o corpus dos homens da variedade carioca (uma ocorrência analisável).

Em síntese o que se pode afirmar é que os diminutivos nos corpora apareceram muito mais no polo subjetivo que no referencial. $\mathrm{O}$ uso dos diminutivos para expressar afeto negativo não é um recurso produtivo na variedade madrilena.

Os resultados no gráfico abaixo dizem sobre os valores absolutos de cada categoria morfopragmática presente nas variedades investigadas. As ocorrências com funções sobrepostas foram desmembradas de modo a possibilitar a visualização e comparação de cada função nos corpora. 
Gráfico-1

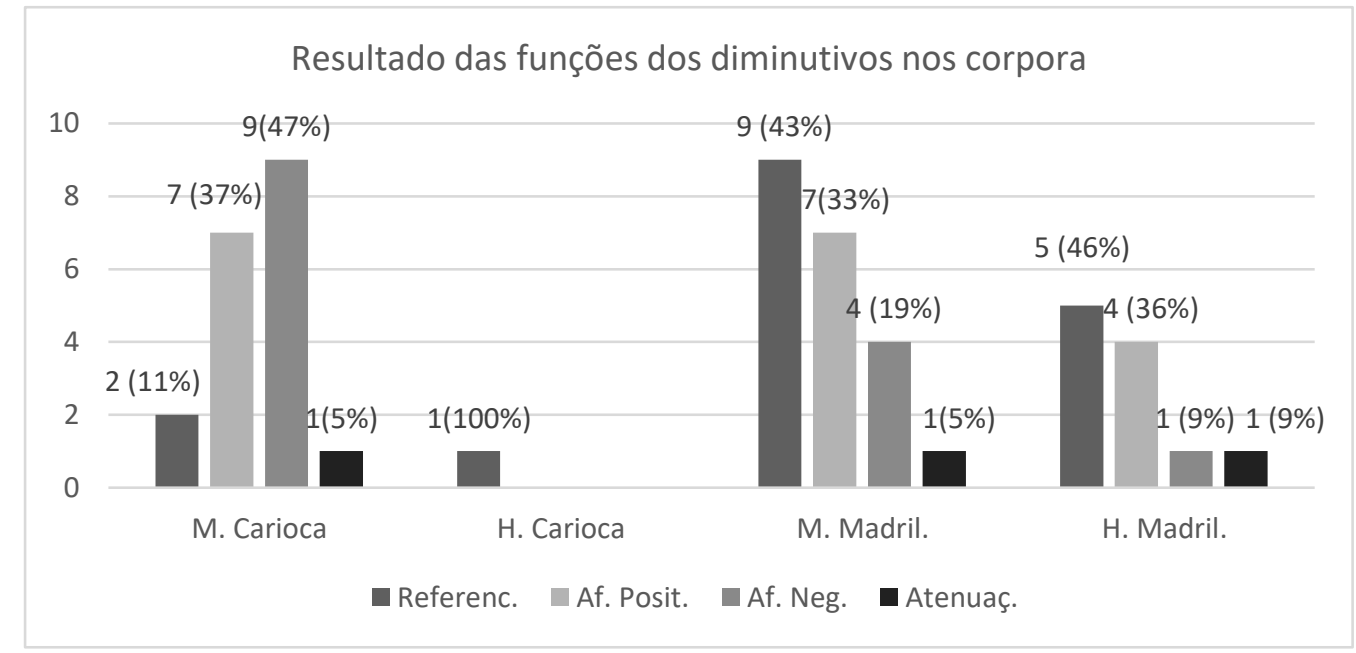

Podemos afirmar que os usos morfopragmáticos dos diminutivos divergem nas entrevistas cariocas e madrilenas, afinal, enquanto o caráter referencial permanece atrelado ao sufixo diminutivo em espanhol para ambos os gêneros, em português a expressão da subjetividade por meio dos diminutivos é preponderante no corpus feminino.

\section{CONSIDERAÇÕES FINAIS}

O uso predominante de diminutivos com funções subjetivas nos dados do português e a alta produtividade dos diminutivos com funções subjetivas no corpus madrileno, ainda que sobrepostas ao valor dimensional, confirmam a hipótese de que, em uma atividade como a entrevista sociolinguística, o entrevistado utiliza o diminutivo em contextos em que esse uso serve para projetar aspectos da face do entrevistado.

Nas entrevistas, o diminutivo não é tanto um atenuador de ameaças à face como afirmam Brown e Levinson (1987), mas sim pista contextual que contribui para o trabalho de construção de face. 
As entrevistadas do corpus carioca usam os diminutivos dentro de contextos em que querem marcar o grupo do qual não fazem parte, atribuindo ao grupo do outro um afeto negativo por meio, dentre outros elementos, das formações diminutivas. Coerente com o ethos + consensual desta comunidade de fala, as entrevistadas evitam ser taxativas na expressão de sua opinião e optam pela indiretividade, fazendo uso, dentre outras coisas, dos diminutivos.

No corpus madrileno, os diminutivos atuam na projeção de uma comunidade de fala que valoriza a autonomia, não só para expressar seus juízos de valores, mas para marcar uma independência que vai do concreto (financeiro) ao mais abstrato (as ideias).

Porém se nos focamos nos homens de ambas as variedades, observamos que os diminutivos não são tidos como um recurso produtivo para a expressão de subjetividade, são muito mais marcadores de dimensão.

\section{REFERÊNCIAS}

ALONSO, A. Noción, emoción, acción y fantasía en los diminutivos. Estudios lingüísticos. 3.ed. Madrid: Gredos, 1967.

BECHARA, E. Moderna gramática portuguesa. Rio de Janeiro: Lucerna, 2005.

BEINHAUER, W. La expresión Afectiva. In: MORTON, F. H. El español coloquial. Editorial GREDOS. Madrid, 1985.

BRAVO, D. Actividades de cortesía, imagen social y contextos socioculturales: una introducción. In: BRAVO, D. Estudios de la (Des)Cortesía en español. Estocolmo-Buenos Aires, EDICE, 2005, p. 98-108.

BRIZ, A. Eficacia, imagen social e imagen de cortesía. In: BRAVO, D. Estudios de la (Des)Cortesía en español. Estocolmo-Buenos Aires, EDICE, 2005, p. 53-86.

BROWN, P.; LEVINSON, S. C. Politeness: some universals in language usage. Cambridge: Cambridge University Press, 1987.

DRESSLER, W. U.; BARBARESI, L. M. Pragmatic explanations in morphology. In.: PIRRELI, V.; PLAG, I.; DRESLER, W. U. (eds.). Word Knowledge and Word Usage: A Cross-Disciplinary Guide to the Mental Lexicon. Berlin/Boston, De Gruyter, 2020, p. 405-451. 
EZARANI, E. S. Formações X-inho na fala carioca. 1989. Dissertação (Mestrado). Departamento de Letras, Universidade Federal do Rio de Janeiro, Rio de Janeiro.

GOFFMAN, E. A Elaboração da Face. Uma análise dos elementos rituais na interação social. In: FIGUEIRA, S (org.) Psicanálise e Ciências Sociais. Rio de Janeiro: Francisco Alves, 1980, p.70-92.

. A representação do eu na vida cotidiana. 17. ed. - Petrópolis: Vozes, 2009.

GONÇALVES, C. A. V. Flexão e Derivação: o grau. In: BRANDÃO, Sílvia Figueiredo; VIERA, Sílvia Rodrigues. (Org.). Ensino de gramática: descrição e uso. 1ed.São Paulo: Contexto, 2007, v. 1, p. 149-168.

GUMPERZ, J. J. Convenções de contextualização. In: GARCEZ, P. M.; RIBEIRO, B. T. (Orgs.). Sociolinguística Interacional. 2.ed. São Paulo: Loyola, 2002, p.149-182.

HANKS, W. F. Pierre Bourdieu e as práticas de linguagem. In: HANKS, W. F. / BENTES, A. C.; REZENDE, R. C.; MACHADO, M. A. R. (Org.). Língua como prática social: das relações entre língua, cultura e sociedade a partir de Bourdieu e Bakthin. São Paulo: Cortez, 2008, p. 33-63.

HERNÁNDEZ FLORES, N. La cortesía en la conversación española de familiares y amigos: La búsqueda de equilibrio entre la imagen del hablante y la imagen del destinatario. 2004. 261f. Tese de Doutorado. Universidad de Estocolmo, Estocolmo.

KERBRAT-ORECCHIONI, C. Atos de Linguagem no discurso. Tradução por Fernando Afonso de Almeida e Irene Ernest Dias. Niterói: EdUFF, 2005.

KOIKE, D. A. Language and social relationship in Brazilian portuguese: The Pragmatics of Polieteness. Austin: University of Texas Press, 1992.

LEVINSON, C. S. Activity types and language. In: DREW, P.; HERITAGE, J. (eds.), Talk at work: Interaction in institutional settings. Cambridge: Cambridge University Press, 1992, p. 66-100.

LOURES, L. H. Análise contrastiva de recursos morfológicos com função expressiva em francês e português. 2000. Tese (Doutorado). Faculdade de Letras, Universidade Federal do Rio de Janeiro, Rio de Janeiro.

MILLS, S. Discursive approaches to politeness and impoliteness. In: Discursive approaches to politeness. Mouton series in pragmatics (8). Berlin, de Gruyter Mouton, 2011, p. 19-56.

REYNOSO NOVERÓN, J. Procesos de gramaticalización por subjetivización: El uso del diminutivo en español. In: Selected Proceedings of the7th Hispanic Linguistics Symposium, DAVID EDDINGTON (ed). Somerville, MA: Cascadilla Proceedings, 2005, p. 79-86.

ROCHA LIMA, C. H. Gramática Normativa da Língua Portuguesa. 45.ed. Rio de Janeiro: José Olympio, 2006.

ROCHA, L. C. Estruturas morfológicas do português. Belo Horizonte: UFMG, 1998.

SANTERO, C. G. O uso do Diminutivo em uma interação face a face: análise comparativa em corpora orais das variantes madrilena e carioca. 2011. 82f. Dissertação (Mestrado 
em Línguas Neolatinas). Universidade Federal do Rio de Janeiro, Rio de Janeiro, RJ, 2011.

SARANGI, S. Tipos de atividade, tipos de discurso e hibridismo interacionais: o caso do aconselhamento genético. Em:. SARANGI, S; e COULTHARD M. (Eds.), Vida Social e Discurso. London: Longman, 2000, p. 1-57.

SOLER ESPIANUBA, D. La expresividad en el sistema de sufijación. In: CUADERNOS CERVANTES, 8. Publicado em 1996. Disponível em: $<$ http://culturitalia.uibk.ac.at/hispanoteca>. Acesso em: 23/03/2009.

SPENCER-OATEY, H. Theories of identity and analysis of face. Journal of Pragmatics, [S.1.], n.39, p. 639-656, 2007.

TERKOURAFI, M. Beyond the micro-level in politeness research. Journal of Politeness Research, [S.1.], n.1, p.237-262, 2005.

TANNEN, D.; WALLAT, C. Enquadres interativos e esquemas de conhecimento em interação. In: GARCEZ, P. M.; RIBEIRO, B. T. (Orgs.). Sociolinguística Interacional. 2.ed. São Paulo: Loyola, 2002, p.153-174.

TRIANDIS, H. et alii. Simpatía as a Cultural Script of Hispanics. In: Journal of Personality and Social Psychology. [S.1.]. American Psychological Association Inc, p 13631375. 1984.

TURUNEN, V. A reversão da relevância: aspectos semânticos e pragmáticos de formações diminutivas no português do Brasil. 2009. 192f. Tese. (Doutorado). Departamento de Letras, Pontifícia Universidade Católica do Rio de Janeiro, Rio de Janeiro.

Nota do editor:

Artigo submetido para avaliação em: 16 de setembro de 2020.

Aprovado em sistema duplo cego em: 18 de novembro de 2020. 